\title{
Notas sobre un Libro de Filología Chilena
}

FIlologia es, según el léxico oficial, el "estudio cientíI fico de una lengua y de las manifestaciones del espíritu a que ella sirve de medio de expresión", y es también, "particularmente, estudio científico de la parte gramatical y lexicográfica de una lengua". Según la segunda parte de la primera acepción, la filología comprende la historia y la crítica literarias y todos los problemas de arte relacionados con la expresión oral y escrita del talento humano. Para Lenz (Ensayos filológicos americanos, II, p. 1-2), "la filología, en el significado más lato de la palabra, es la ciencia que indaga el lenguaje de un pueblo; esta indagación puede referirse tan sólo a la forma exterior del idioma, a los sonidos de que consiste, a las formas flexivas que puede emplear, a la manera particular de expresar los juicios por la formación de frases y por la coordinación o subordinación de proposiciones; mirada de este lado, la indagación del lenguaje de un pueblo pertenece a la lingüística en general, la que con relación a cada idioma se divide en tres partes, la fonología, la morfología y la sintaxis. Pero también la indagación puede referirse a las ideas expresadas por el lenguaje, a la manifestación del estado intelectual del pueblo respectivo por medio del idioma; desde este punto de vista la filología abarca la historia literaria; y queda como dominio particular de la filología propiamente tal la ciencia de los métodos que hay que emplear para explicar las fuentes de las cuales derivamos nuestro conocimiento de la lengua respectiva". 
En su acepción amplia ha sido tomada la voz filología en diversas Universidades para designar facultades o institutos en los cuales se estudia no sólo la lengua como organismo de comunicación entre los hombres, sino también los productos artísticos que la utilizan como vehículo, esto es, las letras. En el libro de Guillermo Rojas Carrasco, Filología chilena (Guía bibliográfica y crítica. Ed. de la Universidad de Chile. Imp. y Lit. Universo, Santiago, 1940. 301 pp.), la palabra ha sido tomada en su acepción restringida, ya que no aparecen menciones especiales de crítica literaria ni de historia de la literatura. (1)

Por su tema, la obra que nos ocupa se habría llamado mejor que Filología chilena, Filología del castellano en Chile, ya que en ella, salvo muy pocas entradas, no se describen libros que se relacionen sino con la lengua castellana. Las excepciones más notorias son las de las obras que tratan algunos puntos de filología de las lenguas americanas, y sobre todo de la araucana o mapuche y de la rapa-nui (de la Isla de Pascua), a todas las cuales concede entrada el autor por la relación que han tenido hasta hoy o pueden tener en lo futuro con el castellano hablado en Chile. Pero "filología chilena" stricto sensu debería ser cualquier estudio filológico intentado en Chile, o por autor chileno, cualquiera que fuese la lengua sobre que versa. En esta materia el criterio del autor se muestra poco uniforme, porque ha conservado las producciones sobre lenguas y dialectos ajenos al castellano cuando las autorizaban las firmas de maestros tales como Bello y Lenz, (2) por citar sólo a dos, pero no cuando correspondían a otros autores.

El señor Rojas comienza por establecer que su trabajo "no es precisamente una Bibliografía, tarea que exigiría un registro completo de todas las obras de índole filológica aparecidas en Chile", y precisa que su plan, "si incompleto en el sentido bibliográfico, es un poco más ambicioso en otros aspectos, pues tiene la presunción de presentar un cuadro general que permita darse cuenta cabal del desarrollo de los estudios filológicos hechos en nuestro país por chilenos y por extranjeros avecindadoś en él" (p. 9). Fijadas así las 
fronteras, no cabe dudar de que el libro del señor Rojas Carrasco no llena totalmente su programa, ya que las obras que faltan en él le restan la amplitud debida. Para llegar a "presentar ese cuadro general" el autor debe comentar las obras que recuenta, y lo hace efectivamente, pero sin la precisión científica que hubiera sido de desear. De cada libro o artículo de revista que ha llegado a su conocimiento el señor Rojas Carrasco hace una reseña ligera, que en algunos casos es de pocas líneas y que en otros muy excepcionales se extiende a varias páginas. Pero en estos estudios no se descubre una doctrina propia, ni están ellos trabados en forma sistemática, hasta el punto de que en algunos casos no ofrecen utilidad mayor para la consulta. Es de suponer que un estudio más detenido y metódico hubiera obligado al autor a escribir no trescientas sino mil páginas, pero sin haber intentado eso resulta un poco fuerte la frase que hemos citado poco más arriba.

Veamos un punto concreto de doctrina.

Hay una vieja disputa entre los filólogos acerca de lo que se debe entender por gramática. ¿Es una ciencia, como pretenden, entre otros, los autores de la escuela alemana, tan gallardamente representados en Chile por don Rodolfo Lenz? ¿O es un arte, como dice la famosa definición de Bello? La Academia Española puso el peso de su autoridad en favor de esta última definición al decir que gramática es el "arte de hablar y escribir correctamente una lengua", que dice lo mismo que Bello, excepto el agregado de "esto es, conforme el uso de la gente educada", que tiene un carácter más local que general y que debe darse por subentendido en la definición académica. No es posible, en efecto, imaginarse que una lengua pueda hablarse y escribirse correctamente si, no se sigue, por los indoctos y por los aprendices, algún cartabón. Para Bello el cartabón era el uso de la gente educada; para la Academia, erigida en autoridad, no puede ser este uso sino en cuanto concuerde con sus propias ensẹnanzas.

Pero hay en la definición académica un vacío notorio. ¿Puede ser sólo arte el de la gramática si todos los fenómenos del lenguaje quedan en su jurisdicción? ¿No habrá al- 
gunos fenómenos que el arte como tal no podrá explicar jamás adecuadamente? A nuestro juicio, no puede hablarse con exclusividad de arte, ni de ciencia, tratándose de la gramática, a no ser que para la parte científica del lenguaje se inventara o se adoptara otra expresión. La gramática es una ciencia en cuanto estudia una lengua en sus expresiones orales y escritas, sin atención al contenido y con relación sólo al acuerdo que haya entre éstas y el espíritu humano; y es un arte cuando, hecho ya ese estudio, adopta por razones utilitarias, formas particulares de expresión que deben ser recomendadas para el uso de aprendices y de indoctos. $\mathrm{Y}$ decimos por razones utilitarias, porque es evidente que hay conveniencia en fijar las formas de la lengua de manera tan inequívoca y clara que hasta los más ignorantes puedan emplearlas con una corrección siquiera relativa. No se trata ahora, como se comprenderá, ni de estilo, ni de amenidad, ni de hecho alguno que toque, siquiera de paso, a la estética del lenguaje. Se trata única y exclusivamente de que una lengua tiene por objeto primordial permitir que los hombres se entiendan, siendo obvio que no habrán de entenderse si cada cual la usa a su manera.

El señor Lenz, que estudió muy a fondo todas estas cuestiones, dijo en su obra ¿Para qué estudiamos gramática? (1912) que "la exposición teórica y sistemática de los principios de un arte no debe llamarse arte sino ciencia", con lo cual, a nuestro parecer, se zanja de una vez por todas el problema. Para el señor Lenz, como es visible en las palabras que hemos copiado (p. 22 del folleto de Lenz y p. 230 del libro del señor Rojas Carrasco), hay un arte de la gramática que versa sobre el uso que se hace de la facultad de hablar tanto en lo oral como en lo escrito y que no puede tener otra finalidad que permitir la cabal inteligencia de los hombres entre sí; y hay una ciencia de la gramática, que es la exposición metódica de los principios de ese arte. $\mathrm{Y}$ es evidente que la gramática como ciencia no puede "imponer leyes según las cuales se deba hablar", como ha dicho el propio señor Lenz, y que esta parte legislativa y coercitiva, por decirlo así, corresponde de lleno a la gramática como arte. 
En estos puntos de doctrina nos parece que el autor no tiene un criterio fijo, ya que se limita a reproducir la enseñanza de cada uno de los escritores a quienes estudia, sin pronunciar el juicio a que pudiera conducir su exposición comparativa. Lo único preciso que en esta materia encontramos en el libro es la sentencia con que termina el estudio de $L a$ oración y sus partes, el libro cumbre de Lenz. "De lo dicho-escribe el señor Rojas Carrasco-se desprende que no es éste un libro cuya lectura pudiera recomendarse siquiera a un estudiante de humanidades, $y$ seguramente habrá muchos adultos que al estudiarlo no cosecharán sino una mayor confusión en punto a doctrina. Es demasiado complicado. Es obra para especialistas, y exige, además, una biblioteca de obras eruditas en que hay que ampliar y comparar teorías" (p. 233). Participamos casi del todo de la opinión del señor Rojas Carrasco, y creemos que merece un aplauso el hombre valiente que se ha atrevido a decir tal cosa entre nosotros. La fama, ciertamente muy merecida, del profesor Lenz, ha auspiciado, seguramente sin el asentimiento del distinguido estudioso, una incertidumbre gramatical que hace daño al país. Los jóvenes que leen a una edad indebida, o sin la preparación conveniente, el libro del doctor Lenz, no sólo se quedan en ayunas respecto del alcance de la mayoría de las observaciones que contiene, sino que además pierden la pista en sus estudios posteriores. En el libro ha dicho el autor que la gramática no es arte sino ciencia, y que a una ciencia no le corresponde dar leyes para que se hable y se escriba bien, de donde parece desprenderse que hablar y escribir mal no es reprobable. Ha revuelto además la división tradicional de las partes de la oración, en virtud de investigaciones muy prolijas de gramática comparada, y en reemplazo de ella ha ofrecido otra que el joven estudiante no ha conocido nunca antes ni encontrará después repetida en parte alguna. $Y$, finalmente, ha cedido a la tentación de hacer algunas definiciones que sólo el respeto que merece la obra del hombre de ciencia impide llamar macarrónicas: "La oración es la expresión fonética (o linguiística) de la descomposición intencional de una representación total en sus elementos lógicamente relacionados". 
¿Qué le pasa al joven estudiante después de este chaparrón de términos que no están a su altura? Que pierde la fe en la gramática como arte, y hasta la desprecia como añejez indigna de los tiempos en que vive; pero que no alcanza a comprender la gramática como ciencia, ya que para ello sería preciso, de una parte, alguna mayor explicación que la que le ofrece el doctor Lenz, y, de otra, que todos los estudios de gramática hechos desde la infancia fueran adecuados a las exigencias 'científicas que el profesor alemán plantea, y no, como ocurre, a las enseñanzas de Bello y de la Academia. La incertidumbre gramatical en que vivimos comienza sólo ahora a producir sus frutos. Se desprecian la puntuación y la ortografía, se cometen los solecismos más intolerables, la lengua se llena de todo género de alteraciones grotescas, entre las cuales la invasión de los barbarismos es sólo una parte, y acaso menuda, del conjunto, y se habla y escribe, en fin, en una plena libertad que se parece mucho a la anarquía y que debe conducir a que dentro de poco nadie entienda a nadie.

Este último supuesto es, como se comprenderá, la reductio ad absurdum. No ocurrirá seguramente que se realice, porque son muy pocos los que leen el libro del señor Lenz y muchos, en cambio, los que, a espaldas de él, no saben de gramática otra cosa sino que es un arte de hablar y escribir correctamente, esto es, conforme al uso de la gente educada y... conforme a las enseñanzas del profesor. Pero lo grave es que el profesor se ha formado en esta escuela de incertidumbre gramatical y que entre los del gremio no faltan quienes la divulgan en escuelas y liceos. Las autoridades educacionales harían bien si tomaran a su cargo este problema y dictaran instrucciones precisas para acomodar la instrucción a las necesidades generales y no sólo al estudio abstracto de los especialistas. Desdichadamente, en esta materia se ha concedido de manera oficial una licencia que parece llamada a generalizar la incertidumbre. El señor Rojas Carrasco, en efecto, copia una parte del programa vigente para la educación secundaria de Chile (1935) que así lo establece: "Respecto a teorías gramaticales - sin desconocer el derecho 
que tiene el profesor de seguir las que crea más exactas- se recomienda que en la clase se expongan doctrinas modernas, aceptadas por grandes filólogos e incorporadas ya, en su mayor parte, en los textos oficiales de la Academia Española" (p. 235 del libro del señor Rojas Carrasco).

La frase puesta entre guiones en el programa huelga por entero. No es indispensable reconocer la libertad que los profesores tienen para pensar de la ciencia que explican lo que les venga en ganas. El objeto del programa es indicar lo que debe enseñarse en la clase, y claro está que lo que haya de enseñarse debe ser una cosa precisa, bien definida, sin ambigüedad ni salvedades de ninguna especie. La recomendación para que en la clase "se expongan doctrinas modernas, aceptadas por grandes filólogos e incorporadas ya, en su mayor parte, en los textos oficiales de la Academia", es una invitación al caos. ¿Por qué doctrinas modernas si, como es posible, hay adquisiciones de la ciencia gramatical que han resistido a los siglos? ¿Y quiénes son esos grandes filólogos respecto de los cuales no se ofrece dato alguno para identificarlos? ¿Los conocen los estudiantes del ramo de que más tarde serán profesores, o tienen noticias de ellos sólo a través de Bello y de Lenz? Por lo demás, sus doctrinas ¿en qué grado han sido incorporadas en los textos oficiales de la Academia? ¿Quién - hombre o corporación- ha estudiado el punto hasta poder precisar las doctrinas de esos filólogos que la Academia ha aceptado? Todo esto es impreciso por no decir nebuloso, y parece calculado para acrecentar la incertidumbre de los estudiantes y de los profesores. Por eso no es de extrañar que los estudios de estos ramos hayan decaído tanto entre nosotros como resulta ya palpable-por decirlo asíen los escritos contemporáneos.

Para no ensanchar demasiado su estudio, el autor prescindió en el escrutinio de todos los textos puramente escolásticos de gramática, de métrica y de otros temas filológicos, aun cuando conservara indicación expresa de la Gramática de Bello y algunos otros estudios más, de índole preferentemente escolar. Es ésta sin duda alguna una de las mayores deficiencias de este trabajo bibliográfico, ya que invalida 
su empleo como una guía histórica de la aplicación que en Chile han tenido las diversas doctrinas gramaticales. (4) No podemos saber, en efecto, siguiendo las indicaciones del señor Rojas Carrasco, cuáles de esos textos se han inspirado en la Academia por ser anteriores a Bello, ni cuáles, siendo posteriores, han dejado de considerar a Bello como guía, ni en cuáles se ha atendido, a un mismo tiempo, a las enseñanzás académicas y a las del ilustre venezolano. No podemos saber tampoco en qué momento preciso comenzó a separarse la enseñanza gramatical dominante en Chile de las doctrinas de Bello para abrazar nuevamente las de la Academia, ni tampoco si ha habido o no influencia directa de Lenz en la redacción de textos destinados a la enseñanza. No puede decirse que estos pormenores sean baladíes. Parece, por lo contrario, que son indispensables para reconstituir, siquiera en aproximativo esquema, la historia de las vicisitudes que han tenido en Chile las doctrinas gramaticales, lo que no puede ser desestimado en una obra que se titula Filología chilena, y que lleva el subtítulo de Guía bibliográfica y crítica.

En la parte que el señor Rojas Carrasco dedica al "problema ortográfico" (p. 13-56) podemos ver otra prueba del criterio erróneo, a nuestro parecer, que ha guiado las exploraciones que se resumen en este libro. El autor expone detenidamente las diversas tentativas realizadas en Chile para aclimatar una ortografía propia, o provincial, que ha tenido diversos nombres y que generalmente se llama reformada o de Bello. Y al término de su estudio, el autor reproduce en parte el decreto núm. 3876, de 20 de junio de 1927, firmado por todos los Ministros de Estado, que restableció como obligatoria en Chile la ortografía de la Academia Española. Lo curioso es que en lugar de saludar este decreto como una muestra palmaria de buen sentido, lo comenta en términos de que no podemos en modo alguno participar.

"El decreto mencionado - escribe el señor Rojas Carrasco (p. 55) - declara que 'sin entrar a contemplar los aspectos de orden técnico' deben tenerse presentes tres consideraciones: la mayoría de los impresos castellanos usan la ortografía académica; la ortografía de Bello es 'rechazada sis- 
temáticamente en toda publicación que deba salir al extranjero', y los diccionarios y enciclopedias se encuentran escritos con el sistema académico. No vamos a discutir la exactitud de estas consideraciones o considerandos -el segundo de los cuales no es totalmente efectivo-, pero no estará de más dejar constancia del verdadero caos que tal decreto trajo como consecuencia inmediata: gente que gozaba de un bien merecido prestigio de cultura, sin excluir a los profesores, desde ese mismo instante resultaron 'oficialmente' ignorantes en cuestiones ortográficas, porque es bien difícil que gente ya madura pueda adoptar de la noche a la mañana una nueva manera de escribir sin incurrir en frecuentes errores; otros, y fueron los más, se contentaron con poner $y$ como preposición y al final de palabras, y con colocar $g$ y $x$ por todas partes, y resultó así una cosa que no era ni ortografía chilena ni académica. Tal situación aún no termina completamente. Todavía, algunos fervorosos partidarios de la ortografía de Bello se desentendieron del decreto y siguen usando el sistema chileno".

En este comentario del señor Rojas Carrasco hay casi tantos errores como palabras, y se nos permitirá comentarlos a nuestro turno brevemente.

1. Era obvio que el decreto no podía "entrar a contemplar los aspectos de orden técnico" porque ni tal cosa es lo propio de un instrumento administrativo, ni lo que se trataba de corregir era tan técnico que digamos. Era más bien práctico, empírico. Se trataba sólo de dotar a los chilenos de un orden ortográfico que les quitara el sambenito de ignorantes de que gozaban en todos los países de lengua española por su insistencia en el empleo de un sistema ortográfico que no es el usual en aquéllos y que había fracasado ya en su intento, sin duda muy plausible, de conquistar los sufragios de todo el mundo hispanoparlante. La reforma debería quedar derogada desde el momento mismo en que no encontraba acogida fuera de Chile, ya que siempre fué visible que no tendría viabilidad alguna mientras no hubiese plena aquiescencia en todos los pueblos que hablan español para adoptarla en su integridad. 
2. El señor Rojas Carrasco habla del caos que el decreto trajo como consecuencia. ¿Hemos leído mal? El decreto no ha traído caos alguno sino que es el primer paso para terminar con el caos existente, que era ya oprobioso para la cultura nacional. Cuando se le promulgó la enseñanza oficial de los establecimientos sostenidos por el Estado se hacía conforme la ortografía reformada, (5) pero en los de orden particular no se seguía esa ortografía sino la académica. Los diarios, sin excepción, y casi todas las revistas se imprimían con ortografía académica, y en muchas imprentas se empleaba generalmente ésta y sólo a requerimiento del cliente la reformada. Todos los libros impresos en español que llegaban del extranjero empleaban la ortografía de la Academia, sin excepción alguna. Se había producido, en suma, una situación de bi-ortografismo dañosa para la cultura. Si el uso es lo que prevalece en las lenguas, y la ortografía académica era más usada que la reformada, lo único procedente para terminar con el caos era extirpar la segunda. El decreto lo hizo. ¿Cómo puede hablarse entonces de que trajo el caos?

3. El señor Rojas Carrasco se conduele de aquellos a quienes se hizo pasar desde entonces como "oficialmente ignorantes en cuestiones ortográficas, porque es bien difícil que gente ya madura pueda adoptar de la noche a la mañana una nueva manera de escribir sin incurrir en frecuentes errores". Lo mismo pasó cuando la autoridad educacional, en tiempos de Bello, adoptó la reforma de éste y la hizo pasar por obligatoria. Con la diferencia de que, por las razones anotadas ya más arriba, los ignorantes de entonces se veían reforzados por todas las publicaciones impresas con ortografía académica que llegaban a sus manos, y los que así llama hoy el señor Rojas Carrasco no tienen ese refuerzo.

4. Es verdad que hay algunos escritores $-y$ de ellos, ¡curioso fenómeno!, varios se sientan en la Academia Chilena de la Lengua-que siguen empleando la ortografía reformada, y que de allí salen engendros tan extraños como extricto y muger. Pero vale la pena no olvidar que el decreto no tiene sino 13 años de vigencia y deben esperarse todavía algunos más para aquilatar sus efectos. No es verdad, 
en cambio, que haya resultado "una cosa que no es ni ortografía chilena ni académica". Los que se hayan resistido a aprender la ortografía de la Academia pueden, si quieren, singularizarse con el uso de la reformada, pero de que la uniformidad en torno a la doctrina académica se producirá a corto plazo, no cabe dudar un instante. Día llegará en que los jóvenes de hoy sean hombres y en que también - todos somos perecederos- hayan desaparecido hasta los más tenaces defensores del sistema de Bello, y entonces esos hombres de mañana se preguntarán con extrañeza qué mal microbio infectó al país cuando se dejó administrar una reforma que iba a singularizar odiosamente su producción intelectual entre todas las demás nacidas en países de lengua española. No habrá entonces caos sino uniformidad, es decir, se habrán eliminado los escollos para que el chileno se entienda bien con españoles, mexicanos, argentinos, peruanos y uruguayos.

No compartimos, pues, la adhesión que el señor Rojas Carrasco parece manifestar a esa inútil y engorrosa reforma, y aplaudimos, por elementales razonès de pulcritud, el decreto que en 1927 puso la primera piedra para terminar con la ortografía provincial que prevaleció en Chile durante una mitad del siglo XIX.

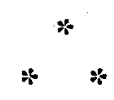

Muchos son los estudios filológicos de que tenemos noticias y que han escapado al escrutinio del señor Rojas Carrasco, con lo cual resulta que algunos de los problemas que ha tocado el autor quedan incompletamente presentados en su obra. Por eso, y sólo por eso, citamos algunos autores de los cuales faltan en este libro las obras que se indican, sin pretender por esto que son ellas las únicas que el señor Rojas Carrasco ignoraba u olvidó al escribir su estudio.

EDUARDO DE LA BARRA: Elementos de métrica castellana, 1887, la obra fundamental del autor en esta materia, premiada como se sabe en el Certamen Varela de ese año; 
Estudios, sobre la versificación castellana, 1889; Nuevos estudios sabre la versificación castellana, $1892 ;$ El endecasílabo dactílico, 1895, uno de los más famosos trabajos del señor De la Barra, como que refuta a "Clarín" (Leopoldo Alas) para defender un verso que Rubén Darío restauró en la lírica española; Estudios de rítmica moderna, 1897; El sistema métrico-rítmico de la antigua versificación castellana, 1897; Estudios de rítmica moderna. Los versos compuestos de cláusulas ritmicas heterogéneas, 1898. Esto por lo que se refiere a la métrica. Otros temas también quedan fuera del escrutinio: Problemas de fonética, 1894; Del correcto silabeo castellano, 1897; Reforma radical de la acentuación castellana, 1898; Primores de la lira antigua 1894; Ruy Diaz de Vivar, Cantar de gesta, 1900, etc., etc.

FRANCISCO J. CAVADA: Ligero estudio acerca de algunas especialidades de lenguaje del Quijote, 1936.

FRANCISCO GUERRERO Y CLEMENTE CANALES: Raíces griegas y latinas, 1936; hay edición aumentada y corregida en 1940.

FEDERICO HANSSEN: Das Possessivenpronomen in den altspanischen Dialeltten, 1897 (el señor Rojas Carrasco cita sólo la traducción castellana publicada al año siguiente); Ueber die altspanischen Praeterita vom Typus ove pude, 1898; $Z$ ur spanischen und portugiessischen Metrik, 1900, estudios los tres publicados en Chile, aun cuando escritos en lengua alemana.

RODOLFO LENZ: Enseñanza de idiomas extranjeros, 1893; Metodología para la enseñanza inductiva del francés, 1894, en colaboración con don Antonio Díez; Proyecto de programa de castellano, 1899; Proyecto para la revisión de los programas de idiomas extranjeros, 1899, y Memorias sobre las tendencias de la enseñanza del Idioma Patrio en Chile, 1899. Nos permitimos llamar la atención hacia los tres últimos estudios, que son sin duda de los más sustanciosos que publicó el señor Lenz y que han tenido innegable repercusión en el curso que se ha dado a los programas de estudios de los Liceos en lo que va corrido del siglo. 
AURELIO MURILLO N.: Crítica a la XIII edición del Diccionario de la Real Academia Española, 1900. No ha salido, al parecer, sino el primer cuaderno de esta obra, con 20 páginas, que comprende un estudio preliminar y observaciones sobre palabras ordenadas en la letra $A$.

JULIO SAAVEDRA MOLINA: Repeliendo la Invasión, 1908, con artículos sobre filología y metodología de las lenguas vivas; $E l$ verso que no cultivó Rubén Dario, 1933; Los hexámetros castellanos y en particular los de Rubén Dario, 1935.

CARLOS VICUNA: Tratado elemental de análisis lógico de la proposición castellana, 1915. Hay ediciones sucesivas hasta la tercera, de 1926, que es la última que conocemos. En el texto del señor Rojas Carrasco se cita (p. 22021) El análisis castellano, por don Sandalio Letelier, del cual dice el autor que "fijó la doctrina que... se respetó y practicó en nuestros colegios en cuanto a análisis lógico". ¿No podría haberse dicho algo semejante del libro del señor Vicuña, que por 25 años sucesivos ha tenido el mismo papel que el autor concede, en otra parte de la historia filológica de Chile, al trabajo del señor Letelier?

JULIO VICUNA CIFUENTES: Estudios de métrica española, 1929. Del mismo libro se publicó además aparte el segundo fragmento, titulado Epitome de versificación castellana, el mismo año. Los estudios que aparecen en la primera parte del libro, titulada Artículos de polémica, habían sido publicados por el autor en varias fechas que se conservan en la recopilación, $y$ hay tiradas aparte.

ROBERTO VILCHES ACUNA: Tratado de raices greco-latinas, 1936. Hay segunda edición, en 1940, con el título plausiblemente modificado: Raices griegas y latinas.

Raúl Silva Castro, Universidad de Chile, Santiago. 
(1). - Vale la pena citar algunas obras en las cuales es posible encontrar más luces sobre la ciencia de que trata esta obra. Una excelente comparación de los términos ingleses scholar, philologist y pbilologer y de los griegos filologos, grammaticos y kritikos, y una definición de la Modern "Philology" se encontrará en el cap. primero de A History of Classical Scholarship, por Sir John Edwin Sandys, III ed., Cambridge University Press, 1921, vol. I. Un estudio semejante, aunque más brevẹ, aparece en Filología Classica greca e latina, por Virgilio Inama, Milano, Hoepli, 1894, p. 1 y sigs. $Y$ un ensayo completo y claro, con menor aparato erudito pero con mayor profundidad de puntos de vista, es el que ofrece La Pbilologie Classique. Six conférences sur l'objet et la méthode des études superieurcs relatives à l'antiquité grecque et romaine, por Max Bonnet, Paris, E. Klincksieck, 1892, en su segunda lección, Histoire de la Philologie, p. 37 y sigs. Por lo demás, la tercera lección de esta misma obra, por todos conceptos excelente, titulada Grammaire, Rbétorique et Poetique, p. 71 y sigs., es también eminentemente aplicable al estudio que nos ocupa. $Y$, en fin, sin llegar a tantas honduras, conviene recordar la definición que trae el Larousse du XX.e siècle: "Science d'une ou de plusieurs langues au point de vue de la grammaire empirique, de la critique textuelle et de l'bistoire littéraire". Esta definición, más sintética y clara que la de la Academia Española mencionada en el texto, nos indica que el señor Rojas ha tomado sólo una parte del contenido de la filología en el estudio a que se refieren estas notas.

(2).-Pero, como se verá en el sitio oportuno de este artículo, también faltan producciones de esos autores, $\mathrm{y}$ de muchos otros que han escrito sobre la materia en Chile.

(3).-Apartemos lo propiamente macarrónico de la definición, tal vez no imputable al talento literario propio del señor Lenz, que tiende generalmente más a la amenidad que a la pesadez, pero sí a la escuela filológica en que se había formado. ¿Qué quiere decir eso de "expresión fonética (o lingüística)"? Lo fonético es una parte de lo lingüístico: un mudo puede saber cualquier idioma, pero como no puede articular no le alcanzan los aspectos fonéticos del mismo. ¿Diremos por eso que no conoce ese idioma? La misma observación es aplicable al que estudia un idioma extranjero lo suficiente para leerlo en lo escrito sin llegar a dominar su pronunciación. ¿Nos atreveremos a decir que lo ignora? No parece discreto, pues, hablar de "expresión fonética (o lingüística)" si la fonética es sólo una provincia de la lingüística.

(4).-El modelo para obras como la que ha escrito el señor Rojas Carrasco lo dió ya más de cuarenta años a la fecha el trabajo, justamente célebre, del Conde de la Viñaza. Me refiero, como se comprenderá, a la Biblioteca Histórica de la Filología Castellana. Obra premiada por voto unánime en público certamen de la Real Academia Española 
y publicada a sus expensas. Madrid, 1893, un vol. de XXV más 1115 páginas, en las cuales se cuentan nada menos que 2152 columnas de descripciones de libros y folletos. El autor de este estudio no omitió por cierto los tratados escolares: de ellos hay nutrida copia en el Libro Segundo de la obra, titulado De la Gramática, que se inicia por cierto con la descripción de la Gramática Castellana de Nebrija en su venerable edición de 1492, coetánea del descubrimiento de América. Y no contento el autor con describirla, la transcribe en gran parte, en obsequio al lector moderno, que tiene sin duda pocas posibilidades de dar con un ejemplar de tan raro impreso.

(5).- Sin embargo, recuerdo que en la clase de Castellano del Instituto Nacional, hacia 1917, don Carlos Vicuña empleaba la ortografía académica, y decía a sus alumnos que, con todo el respeto que le merecía la memoria de Bello, nunca enseñaría la disparatada ortografía de la reforma. Y como lo prometió lo hizo hasta que llegó el decreto de 1927 a darle la razón. 
